\title{
Design Options for an ITER Ion Cyclotron System*
}

\author{
D. W. Swain, F. W. Baity, T. S. Bigelow, P. M. Ryan, \\ R. H. Goulding, M. D. Carter, D. C. Stallings, \\ D. B. Batchelor, D. J. Hoffman
}

Oak Ridge National Laboratory, P. O. Box 2009, Oak Ridge, TN 37831

\begin{abstract}
Recent changes have occurred in the design requirements for the ITER ion cyclotron system, requiring in-port launchers in four main horizontal ports to deliver 50 MW of power to the plasma. The design is complicated by the comparatively large antenna-separatrix distance of $10-20 \mathrm{~cm}$. Designs of a conventional strap launcher and a folded waveguide launcher that can meet the new requirements are presented.
\end{abstract}

\section{IN-PORT STRAP ANTENNA}

The ITER port size has recently increased because of a change from 24 TF coils to 20 in the ITER design. Figure 1 shows a view from the plasma of an antenna that can fit in the new port. Each current strap is grounded at its center, and each end is independently fed by vacuum coax. There are four straps toroidally, and four straps (counting each end as an independent strap) poloidally.

An electrical analysis has been done using a lossy transmission line model for the current straps (assumed to have a characteristic impedance of $40 \Omega$ and phase velocity $0.7 \mathrm{c}$ ) and for the vacuum transmission lines (30 $\Omega$ characteristic impedance) (1). The plasma coupling resistance $R^{\prime}$ was computed using the

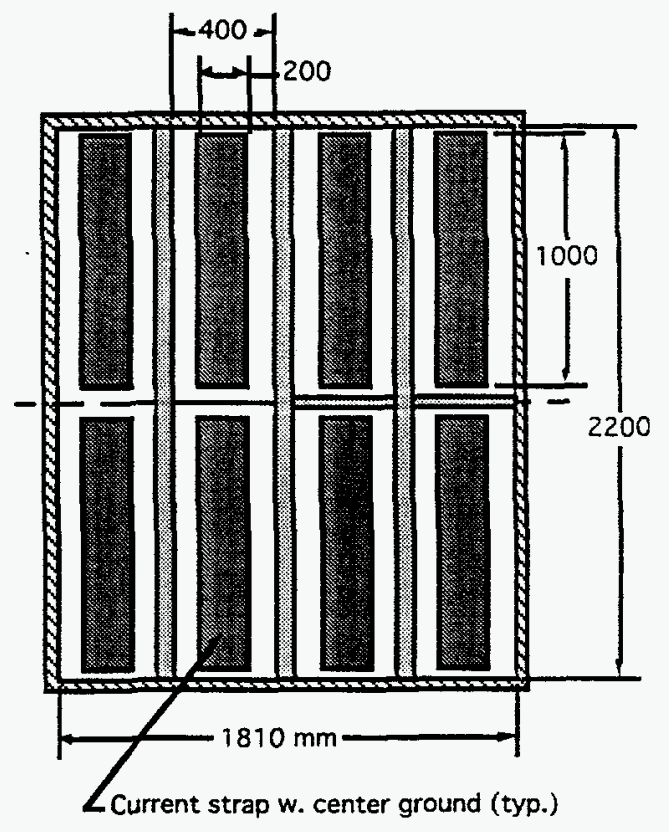

FIGURE 1. View from the plasma of the ITER in-port antenna.

*Research managed by the Office of Fusion Energy, U.S. Department of Energy, under contract DE-AC05-84OR21400 with Martin Marietta Energy Systems, Inc. 


\section{DISCLAIMER}

This report was prepared as an account of work sponsored by an agency of the United States Government. Neither the United States Government nor any agency thereof, nor any of their employees, makes any warranty, express or implied, or assumes any legal liability or responsibility for the accuracy, completeness, or usefulness of any information, apparatus,, product, or process disclosed, or represents that its use would not infringe privately owned rights. Reference herein to any specific commercial product, process, or service by trade name, trademark, manufacturer, or otherwise does not necessarily constitute or imply its endorsement, recommendation, or favoring by the United States Government or any agency thereof. The views and opinions of authors expressed herein do not necessarily state or reflect those of the United States Government or any agency thereof. 


\section{DISCLAIMER}

Portions of this document may be illegible in electronic image products. Images are produced from the best available original document. 
RANT3D code, which has had significant success calculating the $R^{\prime}$ values measured on TFTR and DIII-D using measured density profiles (2). The plasma density profile used is typical of the ITER ignited plasma case (3): inside the separatrix $n(r)=\left(n_{e o}-n_{e d g e}\right)\left[1-(r / a)^{2}\right]^{0.15}+n_{e d g}$; outside the separatrix $\mathrm{n}(\mathrm{r})=\mathrm{n}_{\text {edge }} \exp [-(\mathrm{r}-\mathrm{a}) / \lambda]$. For the results presented here, $\mathrm{n}_{\mathrm{eo}}=1.25 \times 10^{20} \mathrm{~m}^{-3}$, $\mathrm{n}_{\text {edge }}=0.8 \times 10^{20} \mathrm{~m}^{-3}$, and $\lambda=0.02 \mathrm{~m}$.

Figure 2 shows the results of these calculations. The left figure is a plot of $\mathrm{R}^{\prime}$ vs. the gap between the plasma separatrix and the first wall, for $\pi$ and $\pi / 2$ phasing between adjacent current straps. The right figure shows the maximum voltage in the rf system that is required to deliver $50 \mathrm{MW}$ through four ports vs. gap, for $\pi$ and $\pi / 2$ phasing. For a $15 \mathrm{~cm}$ gap, the maximum voltages required to deliver 50 MW to the plasma are $40 \mathrm{kV}$ for $\pi / 2$ phasing and $54 \mathrm{kV}$ for $\pi$ phasing.

Operation with $\mathrm{V}_{\mathrm{rfmax}} \approx 30-35 \mathrm{kV}$ appears well within present-day state of the art. Some experiments report reliable operation up to $\mathrm{V}_{\mathrm{rfmax}}=40 \mathrm{kV}$ (C-Mod) or $45 \mathrm{kV}$ (Tore Supra). Thus, the rf voltages needed for $\pi / 2$ operation are within the operating envelopes of some present-day tokamaks. Operation with $\pi$ phasing would require higher voltages than are presently used, but may be achievable with a reasonable $R \& D$ effort. From the figure, reducing the gap from 15 to $10 \mathrm{~cm}$ would allow operation of the system at the $50 \mathrm{MW}$ level with voltages approximately equal to those in use on some present-day systems.
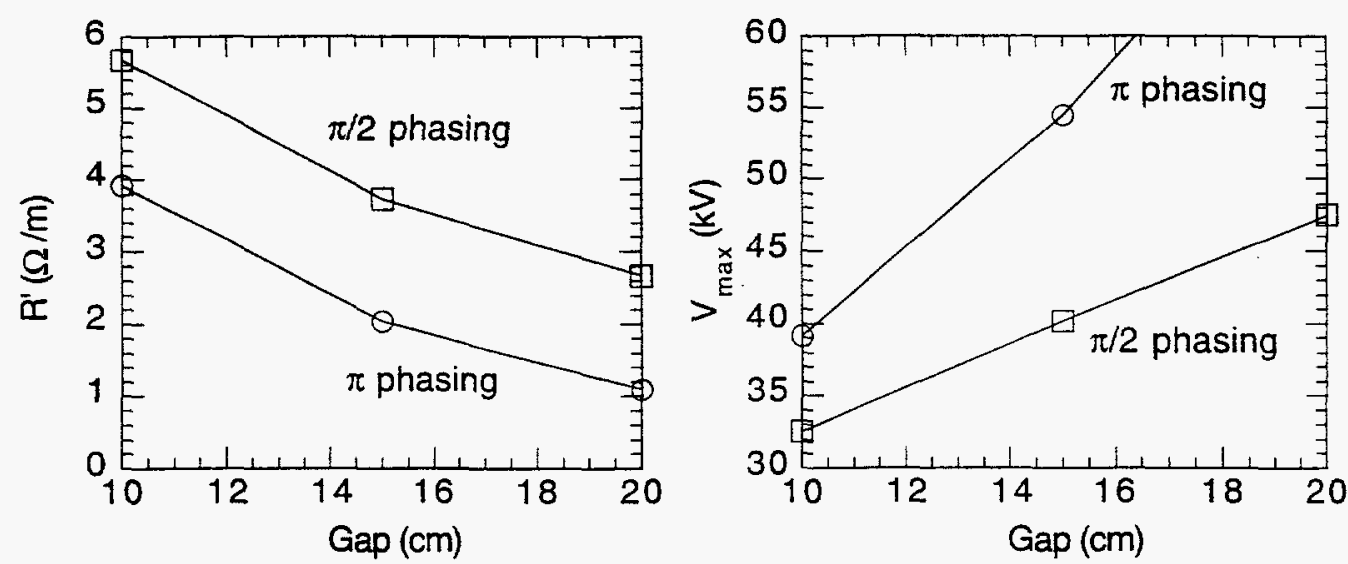

FIGURE 2. Loading resistance vs. separatrix-first wall gap (left), and maximum if voltage vs. gap (right) for phasings of $\pi$ and $\pi / 2$ between adjacent current straps.

\section{FOLDED WAVEGUIDE}

The change to an in-port antenna design has led us to do a preliminary study of using a folded waveguide (FWG) array as an IC launching structure for ITER. The FWG array has the potential for delivering significantly higher power per port than the conventional strap launcher described above (4). Figure 3 shows a layout for a FWG array suitable for installation in an ITER-sized port. 


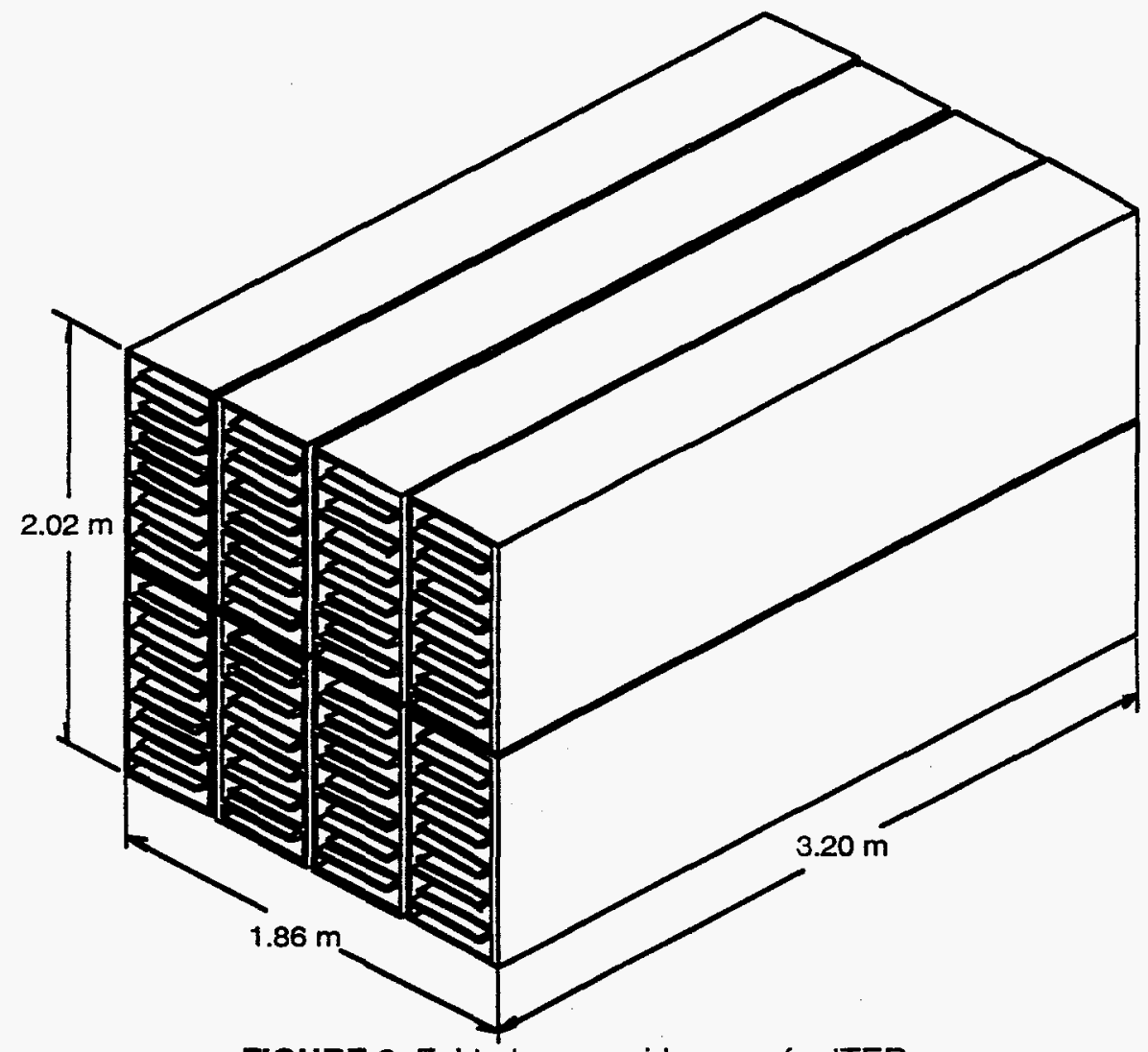

FIGURE 3. Folded waveguide array for ITER

The array consists of a 4 (toroidal) $\times 2$ (poloidal) array of individual folded waveguides. The guides as shown are chosen to resonate at $55 \mathrm{MHz}$; by changing the length of the $3.2 \mathrm{~m}$ side, the resonance frequency can be adjusted to up to about $100 \mathrm{MHz}$. Each FWG is independently driven by a coax line. The magnetic field pattern from a FWG is very similar to that of an ordinary current strap antenna that fits in the same space, so the physics of the launched fast wave should be the same as the physics of waves launched with strap launchers.

For a FWG, the power that can be delivered to the plasma depends on the maximum electric field that can be sustained in the FWG, and on the loading of the FWG by the plasma. A development FWG has been operated on a test stand with electric fields inside the launcher of up to $50 \mathrm{kV} / \mathrm{cm}$ in the presence of a plasma and static magnetic field (5); we take half this value, $25 \mathrm{kV} / \mathrm{cm}$, as the maximum electric field for FWG operation on a fusion device. An electromagnetic model of the FWG is used to relate the maximum electric field (in the center of the FWG) to the maximum magnetic field (at the plasma-facing end of the box).

The antenna coupling code RANT3D is used to calculate the power that can be coupled to the plasma from an antenna structure that generates such a surface magnetic field. To do this, the field pattern of a FWG array is simulated by a series of short current straps stacked poloidally, with currents on each strap 
chosen to give a magnetic field pattern similar to that produced by a FWG. For the array of eight FWG's shown in Fig. 3, with $\pi$ phasing between adjacent toroidal waveguides, and a nominal separatrix-first wall distance of $15 \mathrm{~cm}$, the total power per port is calculated to be $\mathrm{P}_{\text {port }} \approx 32 \mathrm{MW}$.

For different parameters, the power should scale approximately as the values of $\mathrm{R}^{\prime}$ shown in Fig. 2. For example,

$$
\frac{\mathrm{P}_{\text {port }}(\pi / 2)}{\mathrm{P}_{\text {port }}(\pi)}=\frac{\mathrm{R}^{\prime}(\pi / 2)}{\mathrm{R}^{\prime}(\pi)} \approx 1.8,
$$

yielding $\mathrm{P}_{\text {port }} \approx 58 \mathrm{MW}$ for the power that can be delivered from one port with $\pi / 2$ phasing between adjacent FWG's with a $15 \mathrm{~cm}$ gap.

\section{CONCLUSIONS}

The conclusions of this study are cautiously optimistic. With $\pi / 2$ phasing between adjacent current straps, $50 \mathrm{MW}$ can be coupled to the plasma through four ports with a maximum voltage in the rf system of $\approx 40 \mathrm{kV}$. This voltage is within the operating regime of some present-day experiments, and should be achievable in ITER. For $\pi$ phasing, R\&D to develop rf systems that can be operated at $\geq 50 \mathrm{kV}$ will be needed.

A preliminary assessment of a FWG launcher for ITER looks exceptionally promising. For a $4 \times 2$ array of folded waveguides operating at $60 \mathrm{MHz}$ with $\pi / 2$ phasing between adjacent toroidal waveguides, the full $50 \mathrm{MW}$ could be delivered to the plasma from a single port. In addition, the FWCD current drive capability should be as good as that from a conventional strap array. The FWG can only operate at a fixed frequency, unless mechanical tuning elements are introduced into the vacuum (an undesirable option). However, the significant increase in power-handling capability with a FWG array could offset the disadvantage of single-frequency operation.

\section{REFERENCES}

1 Ryan, P. M., et al., "Integrated design and analysis of RF heating and current drive systems", proceedings of this conference.

2 Carter, M. D., et al., "Three-dimensional physics of ICRF launchers for fusion devices", accepted for publication in Nuclear Fusion.

3 ITER Joint Central Team, Detail of the ITER Outline Design Report: Summary and Overall Physics Issues,v.1, section titled "Physics and Plasma Operation Studies", presented to the TAC-4 meeting, 10-12 January, 1994, San Diego.

4 Owens, T. L. , "A folded waveguide coupler for plasma heating in the ion cyclotron range of frequencies", IEEE Trans. Plasma Sci. PS-14, 934-946 (1986).

5 Haste, G. R., et al., "The folded waveguide: a high frequency if launcher", Fusion Eng. and Design, 24, 191-204 (1994). 